\title{
A new aneuretine ant from the Paleocene Paskapoo Formation of Canada
}

John S. Lapolla and Phillip Barden

Acta Palaeontologica Polonica 63 (3), 2018: 435-440 doi:https://doi.org/10.4202/app.00478.2018

While ants were present in the Cretaceous they were relatively rare. This changes dramatically from the Eocene onward when ants rise to the levels of global dominance seen in terrestrial ecosystems today. Their prevalence is well documented in various Eocene, Oligocene, and Miocene fossil deposits, but there is a conspicuous absence of ant-bearing fossil deposits around the Cretaceous-Paleogene boundary. In particular, until this study, there were no definitive ant-yielding deposits between 78 million and 55 million years ago, a 23-million-year gap. This gap is significant because, in addition to spanning a time when ant prevalence increases by an order of magnitude, the fossil rich deposits from the Eocene onward reveal a dramatically different ant fauna from that observed in the Mesozoic. The Paleocene Paskapoo Formation in Alberta, Canada has yielded a variety of fossil arthropod specimens, including a single worker ant fossil. Examination of this fossil indicates it is a species belonging to the now monotypic and relictual ant subfamily Aneuretinae. Napakimyrma paskapooensis gen et. sp. nov. is here described, revealing a species exhibiting a number of interesting and unique morphological features. Its placement as an aneuretine is supported by the presence of a long anterior peduncle of the petiole. A total of 11 fossil aneuretine taxa are now known, but for several, their placement within the subfamily is highly uncertain and needs further study. A discussion of all fossil aneuretine taxa is provided. Given the uncertainty of the apomorphies defining the Aneuretinae, and the fact that fossil species suggest a greater historic morphological diversity for the subfamily than is present now in the single, living species, it is important to consider the need for flexibility in defining synapomorphies for Aneuretinae and any such analysis will need to involve reevaluation of the fossil fauna.

John S. LaPolla [jlapolla@ towson.edu], Department of Biological

Sciences, Towson University, Towson, MD 21252, USA. Phillip

Barden [barden@ njit.edubarden@njit.edu], Department of Biological Sciences, New Jersey Institute of Technology, Newark, NJ 07102, USA. 
Attribution License (for details please see creativecommons.org), which permits unrestricted use, distribution, and reproduction in any medium, provided the original author and source are credited.

PoFif Full text $(324.5 \mathrm{kB})$ 